\title{
Factors influencing mycelial growth of Sclerotium rolfsii
}

\author{
Indramani Bhagat \\ Department of Botany, Post Graduate Campus, Tribhuvan University, Biratnagar, Nepal \\ E-mail: indramani@ntc.net.np
}

\begin{abstract}
Sclerotial blight of tea (Camellia sinensis L.) caused by Sclerotium rolfsii Sacc. is one of the destructive diseases in tea growing areas of the world. In the present investigation, an attempt was made to know the optimum conditions for the mycelial growth of $S$. rolfsii. Factors influencing mycelial growth of $S$. rolfsii were studied with special reference to their growth in different media, variable $\mathrm{pH}$ and variable sources of carbon (viz., 6 types) as well as organic (viz., 4 types) and inorganic (viz., 4 types) nitrogen sources. Maximum growth of pathogen occurred after 8 days of inoculation at $\mathrm{pH}$ 6. Dextrose was the most effective carbon source and yeast extract (organic source) was found most optimum for growth of $S$. rolfsii. Organic nitrogen sources were found to be better than inorganic nitrogen sources.
\end{abstract}

Key words: Sclerotium rolfsii, Camellia sinensis, mycelial growth factors.

\section{Introduction}

Tea (Camellia sinensis L.) is the most important hot beverage in the world today. It occupies a very important position in Nepalese agriculture being one of the major foreign exchange earners of the country. Sclerotium rolfsii is one of the fungal diseases which reduce the quality and quantity of tea production. The fungus is a soil borne pathogen of very aggressive nature. It causes considerable damage of young tea seedlings in the nursery, which is very common in the plains but rare in the hills.

S. rolfsii affects the lower stems and roots of tea seedlings at or near the soil line. During infection whitish mycelial growth of the fungus can be seen at the junction of the branch with the stem close to the soil level, which is the most favoured point of attack. A dark brown lesion on a tea seedling's stem near the soil line is a very early indicator. With time, the disease progresses and a white mycelial web spread over the soil and the basal canopy of the plant, followed by the appearance of sclerotia of mustard seed size on the infected areas. In its advanced stage infection becomes prominent in the root system and subsequently the entire shoot withers and falls and finally the plants die. Seedling death usually occurs rapidly. The fungus can remain in the soil as mycelium, living as saprophytes on diverse organic material and grows actively only in moist soil at moderate to high temperature $\left(25-35^{\circ} \mathrm{C}\right)$. Light brown to yellow, round sclerotia may remain viable for many years. S. rolfsii occurs in diverse soils, has a very wide host range and world wide distribution (Punja, 1985). It infects at least 500 species in about 100 plant families. Diseases caused by $S$. rolfsii are especially rampant where temperatures are sufficiently high to permit the growth and survival of the fungus.

Plants respond to infection by pathogens in a number of ways which are triggered by the initial recognition phenomenon. Successful establishment of the pathogens in host 
depends upon some kind of molecular similarity between two partners (De Vay \& Adler, 1976). However, only certain key common antigens are important in host parasite compatibility (Chakraborty \& Purkayastha, 1983; Chakraborty et al., 1995; 1997; 2002).

\section{Materials and Methods}

\section{Plant material}

Eighteen tea varieties, including five Tocklai varieties, six UPASI varieties and seven Darjeeling varieties, were used for experimental purposes.

\section{Fungal culture}

Virulent culture of Sclerotium rolfsii Sacc was obtained from Immuno-Phytopathology Laboratory, Department of Botany, North Bengal University.

\section{Assessment of mycelial growth}

The mycelial growth on both solid and liquid media for various experimental purposes were as follows.

\section{Solid media}

To assess the growth of $S$. rolfsii in solid media, the fungus was first grown in petridishes, each containing $20 \mathrm{ml}$ of PDA and incubated for 7 days at room temperature. Agar blocks ( $6 \mathrm{~mm}$ dia) containing the mycelia were cut with a sterile cork borer from the advancing zone of mycelial mat and transferred to each petridish containing $20 \mathrm{ml}$ of sterilized solid media. Growth of S. rolfsii was studied in six different solid media i.e., potato dextrose agar (PDA), potato sucrose agar (PSA), carrot juice agar (CJA), Richard's agar (RA), Czapek-Dox agar (CDA) and yeast extract agar (YDA) as described by Dhingra and Sinclair (1985) (Table 1).

Table 1. Studied six different solid medias.

\begin{tabular}{|c|c|c|c|}
\hline \multicolumn{2}{|c|}{ Potato dextrose agar } & \multicolumn{2}{|c|}{ Potato sucrose agar } \\
\hline Peeled potatoes & $40 \mathrm{~g}$ & Peeled potatoes & $40 \mathrm{~g}$ \\
\hline Dextrose & $2 \mathrm{~g}$ & Sucrose & $2 \mathrm{~g}$ \\
\hline Agar & $2 \mathrm{~g}$ & Agar & $2 \mathrm{~g}$ \\
\hline Distilled water & $100 \mathrm{~g}$ & Distilled water & $100 \mathrm{~g}$ \\
\hline \multicolumn{2}{|l|}{ Richard's agar } & \multicolumn{2}{|c|}{ Carrot juice agar } \\
\hline $\mathrm{KNO}_{3}$ & $1.00 \mathrm{~g}$ & Carrot & $2 \mathrm{~g}$ \\
\hline $\mathrm{KH}_{2} \mathrm{PO}_{4}$ & $0.50 \mathrm{~g}$ & Agar & $2 \mathrm{~g}$ \\
\hline $\mathrm{MgSO}_{4} .7 \mathrm{H}_{2} \mathrm{O}$ & $0.25 \mathrm{~g}$ & Distilled water & $100 \mathrm{~m}$ \\
\hline Sucrose & $3.00 \mathrm{~g}$ & \multicolumn{2}{|c|}{ Czapek Dox agar } \\
\hline $\mathrm{KCl}$ & $0.05 \mathrm{~g}$ & $\mathrm{NaNO}_{3}$ & $0.20 \mathrm{~g}$ \\
\hline Agar & $2.00 \mathrm{~g}$ & $\mathrm{~K}_{2} \mathrm{HPO}_{4}$ & $0.10 \mathrm{~g}$ \\
\hline Distilled water & $100 \mathrm{ml}$ & $\mathrm{KCl}$ & $0.05 \mathrm{~g}$ \\
\hline \multicolumn{2}{|c|}{ Yeast dextrose agar } & $\mathrm{FeSO}_{4} \cdot 7 \mathrm{H}_{2} \mathrm{O}$ & $0.05 \mathrm{~g}$ \\
\hline Yeast extract & $0.75 \mathrm{~g}$ & Sucrose & $3.00 \mathrm{~g}$ \\
\hline Dextrose & $2.00 \mathrm{~g}$ & Agar & $2.00 \mathrm{~g}$ \\
\hline Agar & $1.50 \mathrm{~g}$ & Distilled water & $100 \mathrm{~m}$ \\
\hline Distilled water & $100 \mathrm{ml}$ & & \\
\hline
\end{tabular}

All the petriplates were then incubated at $28^{\circ} \mathrm{C}$ and colony diameter of the fungi were studied at 2 day intervals for 8 days. 


\section{Liquid media}

To assess mycelial growth of $S$. rolfsii in liquid culture, the fungus was first grown in a petridish, containing $20 \mathrm{ml}$ of PDA medium and incubated for 8 days at $28 \pm 1^{\circ} \mathrm{C}$. From the advancing zone of the mycelial mat, agar blocks ( $6 \mathrm{~mm}$ dia) containing the mycelia, were cut with a sterilized cork borer and transferred to Erlenmeyer flasks $(250 \mathrm{ml})$ each containing $50 \mathrm{ml}$ of sterilized medium for the desired period at $28 \pm 1^{\circ} \mathrm{C}$. Finally the mycelia were strained through muslin, collected in aluminium foil cups of known weight, dried at $60^{\circ} \mathrm{C}$ for $96 \mathrm{~h}$, cooled in a desiccator and weighed.

\section{Incubation period}

S. rolfsii was grown in Richard's medium (RM) for a period of 20 days. Mycelial growth of the fungus was recorded after 4, 8, 12, 16 and 20 days of incubation at $28^{0} \mathrm{C}$.

\section{pH of medium}

The $\mathrm{pH}$ of the medium usually plays an important role in the growth of all microorganisms. In the present investigation buffer solutions with $\mathrm{pH}$ values ranging from 3.0 to 8.0 were prepared by mixing $\mathrm{KH}_{2} \mathrm{PO}_{4}$ and $\mathrm{K}_{2} \mathrm{HPO}_{4}$ each at a concentration of $\mathrm{M} / 30$. The $\mathrm{pH}$ was finally adjusted using $\mathrm{N} / 10 \mathrm{HCl}$ or $\mathrm{N} / 10 \mathrm{NaOH}$ in each case. The medium and the buffer were sterilized separately by autoclaving for $15 \mathrm{~min}$ at 15 $\mathrm{lb} / \mathrm{in}^{2}$ pressure. Equal parts of the buffer solution and the medium (RM) were mixed before use. Each flask containing $50 \mathrm{ml}$ of the medium was then inoculated with a mycelial block of $S$. rolfsii and incubated for 8 days at $28^{\circ} \mathrm{C}$.

\section{Carbon sources}

The ability of fungi to grow in different media depends on their capacity to utilize the available nutrients, of which carbohydrates are the major ones. It was observed that the growth rate varies with different carbon sources. In this investigation, six different carbon sources (fructose, mannitol, sucrose, starch, maltose, dextrose) were tested for their effects on the growth of $S$. rolfsii. Richard's medium without sugar was used as the basal medium. The equivalent amount of carbon present in $1 \%$ glucose was used as standard and added separately to the basal medium. Data were recorded after 8 days of incubation. A control set without any carbohydrate was also set up. Mycelial dry weight was recorded.

\section{Nitrogen sources}

Nitrogen is the most important nutrient necessary for the growth of any organism. The availability of nitrogen depends to a great degree on the form in which it is supplied. Hence, the most suitable nitrogen source for any particular microorganism can only be determined by testing a number of sources including both inorganic and organic. The effects of complex organic sources (peptone, urea, yeast extract and beef extract) as well as inorganic nitrogen sources (calcium nitrate, sodium nitrate, ammonium sulphate and potassium nitrate) on the mycelial growth of $S$. rolfsii were tested. Richard's medium without nitrogen sources was used as the basal medium. A set without any nitrogen source was considered as control. Data was recorded after 8 days of incubation. 


\section{Results and Discussion}

\section{Media}

Results revealed that the fungus grew well in all media (Plate 1), except in CDA where the mycelial growth was very poor. Maximum growth was recorded in PDA (Plate 1) followed by PSA and YDA but minimum growth was recorded in CDA.

Plate 1. Figures $1,2 \& 3$ (A \& B).

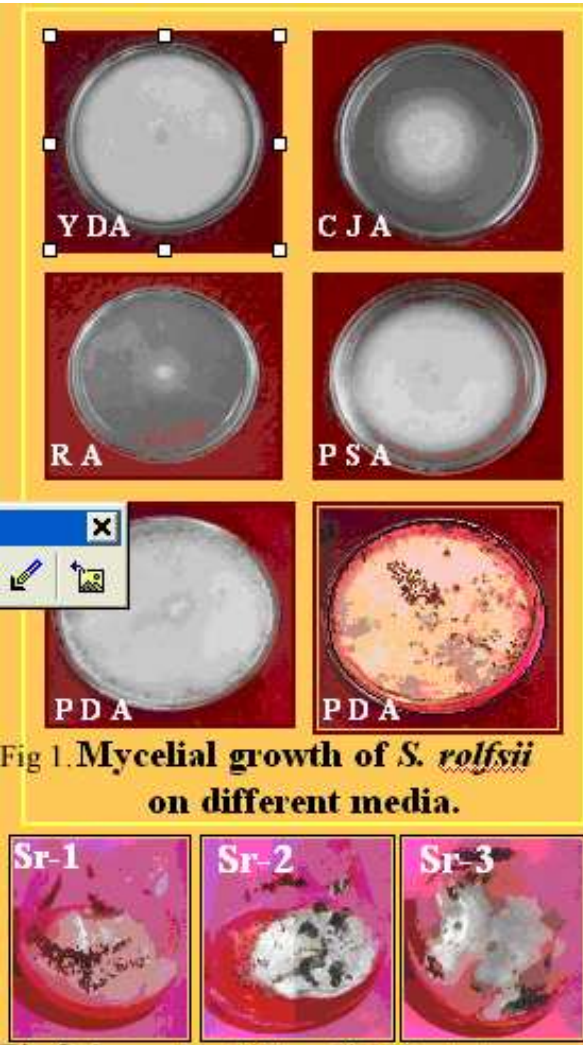

Fig 2.Growth of $S$. rolfsii isolates
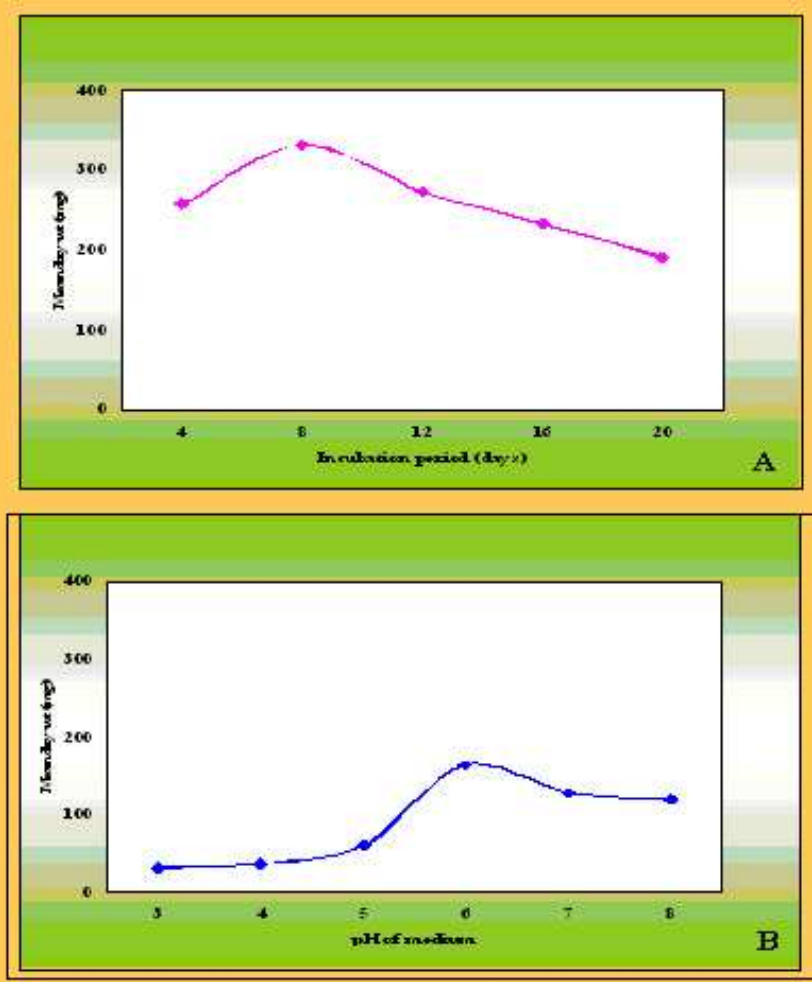

Fig. 3. Effect of incubation period (A) and $\mathrm{pH}$ (B) on mycelial growth of $S$. rolfsii.

\section{Incubation period}

Results have been presented in Table 1 and Plate 1, Fig. 3 A. It revealed that maximum growth occurred after 8 days of incubation after which it declined.

Table 1. Effect of incubation period on mycelial growth of Sclerotium rolfsii.

\begin{tabular}{cc}
\hline Incubation period in days & Mean mycelial dry wt $(\mathbf{m g})^{\mathbf{a}}$ \\
\hline 4 & $258.0 \pm 1.4$ \\
8 & $331.0 \pm 2.8$ \\
12 & $272.0 \pm 0.8$ \\
16 & $233.0 \pm 2.4$ \\
20 & $191.0 \pm 0.8$ \\
\hline
\end{tabular}

${ }^{\mathrm{a}}$ Results are an average of 3 replicates, \pm standard error.

\section{pH of medium}

Results (Table $2 \&$ Plate 1, Fig. 3 B) revealed that $S$. rolfsii grew to a lesser or greater extent in all the $\mathrm{pH}$ tested. Maximum growth was recorded at $\mathrm{pH} 6.0$, while minimum growth occurred at $\mathrm{pH}$ 3.0. Sclerotial germination was very less in a $\mathrm{pH}$ as high as 8.0; however, $\mathrm{pH} 3.0$ and $\mathrm{pH} 4.0$ supported good sclerotial germination. 
Table 2. Effect of pH on mycelial growth of Sclerotium rolfsii.

\begin{tabular}{cc}
\hline $\mathbf{p H}$ of medium & Mean mycelial dry weight $(\mathbf{m g})^{\mathbf{a}, \mathbf{b}, \mathbf{c}}$ \\
\hline 3.0 & $31.0 \pm 1.6$ \\
4.0 & $36.0 \pm 0.8$ \\
5.0 & $61.0 \pm 0.7$ \\
6.0 & $164.0 \pm 1.4$ \\
6.5 & $138.0 \pm 1.6$ \\
7.0 & $129.0 \pm 0.8$ \\
8.0 & $120.0 \pm 2.1$ \\
\hline
\end{tabular}

${ }^{\mathrm{a}}$ Results are an average of 3 replicates, ${ }^{\mathrm{b}}$ Incubation temperature $28^{\circ} \mathrm{C},{ }^{\mathrm{c}}$ Incubation period- 8 days, \pm Standard error.

\section{Carbon sources}

Results given in Table 3 and Plate 2 revealed maximum growth of $S$. rolfsii using dextrose as the carbon source. Maltose and starch also supported comparatively good growth. There was little growth in absence of any carbohydrate.

Plate 2. Figures showing effect of different carbon and nitrogen sources on mycelial growth of S. rolfsii.

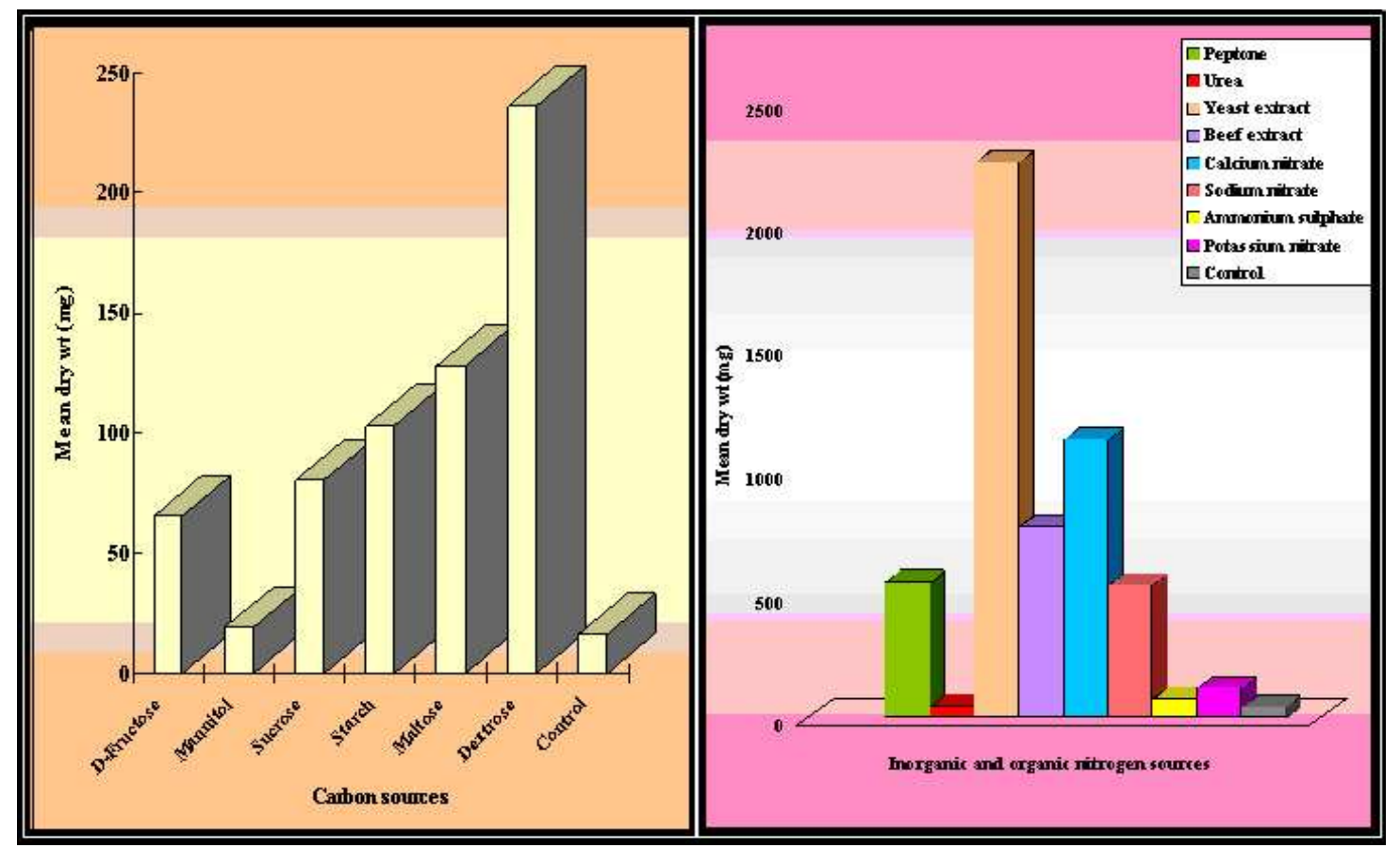

Table 3. Effect of different carbon sources on mycelial growth of Sclerotium rolfsii.

\begin{tabular}{lc}
\hline Carbon sources & Mycelial dry weight $(\mathbf{m g})^{\mathbf{a}, \mathbf{b}, \mathbf{c}}$ \\
\hline D-Fructose & $65.3 \pm 0.5$ \\
Mannitol & $19.0 \pm 0.7$ \\
Sucrose & $80.3 \pm 0.9$ \\
Starch & $103.0 \pm 1.4$ \\
Maltose & $128.0 \pm 1.4$ \\
Dextrose & $236.3 \pm 1.8$ \\
Control (Without carbon) & $16.3 \pm 1.6$ \\
\hline
\end{tabular}

${ }^{\mathrm{a}}$ Results are an average of 3 replicates, ${ }^{\mathrm{b}}$ Incubation temperature $28^{0} \mathrm{C},{ }^{\mathrm{c}}$ Incubation period- 8 days, \pm Standard error. 


\section{Nitrogen sources}

Results (Table 4) revealed that among the organic sources maximum growth was found in yeast extract. In inorganic nitrogen sources maximum growth was obtained in calcium nitrate followed by sodium nitrate (Plate 2).

Table 4. Effect of different nitrogen sources on mycelial growth of Sclerotium rolfsii.

\begin{tabular}{lc}
\hline Nitrogen sources & Mycelial dry weight $(\mathbf{m g}){ }^{\mathbf{a}, \mathbf{b}, \mathbf{c}}$ \\
\hline Organic & \\
Peptone & $551.3 \pm 0.5$ \\
Urea & $47.3 \pm 0.9$ \\
Yeast extract & $2252.7 \pm 1.8$ \\
Beef extract & $776.0 \pm 1.4$ \\
\hline Inorganic & \\
Calcium nitrate & $1130.0 \pm 1.4$ \\
Sodium nitrate & $538.3 \pm 0.9$ \\
Ammonium sulphate & $75.6 \pm 1.2$ \\
Potassium nitrate & $120.0 \pm 0.8$ \\
Control (Richard's Agar without nitrogen) & $43.3 \pm 0.9$ \\
\hline
\end{tabular}

${ }^{\mathrm{a}}$ Results are an average of 3 replicates; ${ }^{\mathrm{b}}$ Incubation temperature $28{ }^{0} \mathrm{C},{ }^{\mathrm{c}}$ Incubation period -8 days; \pm Standard error.

Similar way was used by Chakraborty et al. $(1995,2002)$ for observing the factors influencing spore germination, appresoria formation and disease development in Camellia sinensis by Glomerella cingulata.

\section{Acknowledgement}

The author is grateful to University Grant Commission for the financial assistance to undertake the present study.

\section{References}

Chakraborty, B.N. \& R.P. Purkayastha. 1983. Serological relationship between Macrophomina phaseolina and soybean cultivars. Physiol. Plant Pathol. 23: 197205.

Chakraborty, B.N., P. Basu, R. Das, A. Saha \& U. Chakraborty. 1995. Detection of crossreactive antigens between Pestalotiopsis theae and tea leaves and their cellular location. Ann. Appl. Biol. 127: 11-21.

Chakraborty, B.N., U. Chakraborty, A. Saha, R. Das \& P. Basu. 1997. Detection and management of blister blight of tea. In: Management of threatening plant diseases of national importance (Eds. V.P. Agnihotri, A.K. Sarbhoy \& D.V. Singh). Malhotra Publishing House, New Delhi. pp. 227-235.

Chakraborty, U., R. Das, P. Basu, S. Guha \& B.N. Chakraborty. 2002. Serological cross reactivity between Glomerella cingulata and Camellia sinensis. J. Plantn. Crops. 55(1): $1-7$.

De Vay, J.E. \& H.E. Adler. 1976. Antigens common to host and parasites. Annu. Rev. Microbiol. 30: 147-168.

Dhingra, O.D. \& J.B. Sinclair. 1985. Basic plant pathology methods. CRC Press, Inc. Boca Raton, Florida.

Punja, Z.K. 1985. Biology, ecology and control of Sclerotium rolfsii. Annu. Rev. Phytopathol. 23: 97-127. 